\title{
Article \\ Genome-Wide Identification of the Q-type C2H2 Transcription Factor Family in Alfalfa (Medicago sativa) and Expression Analysis under Different Abiotic Stresses
}

\author{
Jun Pu, Mingyu Li, Pei Mao, Qiang Zhou, Wenxian Liu and Zhipeng Liu *(D)
}

check for

updates

Citation: Pu, J.; Li, M.; Mao, P.; Zhou,

Q.; Liu, W.; Liu, Z. Genome-Wide

Identification of the Q-type $\mathrm{C} 2 \mathrm{H} 2$

Transcription Factor Family in Alfalfa

(Medicago sativa) and Expression

Analysis under Different Abiotic

Stresses. Genes 2021, 12, 1906.

https://doi.org/10.3390/

genes12121906

Academic Editor: Alberto Acquadro

Received: 9 November 2021

Accepted: 25 November 2021

Published: 27 November 2021

Publisher's Note: MDPI stays neutral with regard to jurisdictional claims in published maps and institutional affiliations.

Copyright: (c) 2021 by the authors. Licensee MDPI, Basel, Switzerland. This article is an open access article distributed under the terms and conditions of the Creative Commons Attribution (CC BY) license (https:// creativecommons.org/licenses/by/ $4.0 /)$.
State Key Laboratory of Grassland Agro-ecosystems, Key Laboratory of Grassland Livestock Industry Innovation, Ministry of Agriculture and Rural Affairs, Engineering Research Center of Grassland Industry, Ministry of Education, College of Pastoral Agriculture Science and Technology, Lanzhou University, Lanzhou 730020, China; puj21@lzu.edu.cn (J.P.); limy19@lzu.edu.cn (M.L.); maop17@lzu.edu.cn (P.M.); zhouq2013@lzu.edu.cn (Q.Z.); liuwx@lzu.edu.cn (W.L.)

* Correspondence: lzp@lzu.edu.cn; Tel.: +86-0931-8911-955

\begin{abstract}
Q-type $\mathrm{C} 2 \mathrm{H} 2$ zinc-finger protein (C2H2-ZFP) transcription factors are associated with many plant growth development and environmental stress responses. To date, there have been few analyses of the Q-type C2H2-ZFP gene family in alfalfa (Medicago sativa subsp. sativa). In this study, we identified 58 Q-type C2H2-ZFPs across the entire alfalfa genome, and the gene structure, motif composition, chromosomal mapping, and cis-regulatory elements were explored, as well as the expression profiles of specific tissues and the response under different abiotic stresses. According to their phylogenetic features, these 58 MsZFPs were divided into 12 subgroups. Synteny analysis showed that duplication events play a vital role in the expansion of the MsZFP gene family. The collinearity results showed that a total of 26 and 42 of the 58 MsZFP genes were homologous with Arabidopsis and M. truncatula, respectively. The expression profiles showed that $\mathrm{C} 2 \mathrm{H} 2-\mathrm{ZFP}$ genes played various roles in different tissues and abiotic stresses. The results of subsequent quantitative real-time polymerase chain reaction (qRT-PCR) showed that the nine selected MsZFP genes were rapidly induced under different abiotic stresses, indicating that $\mathrm{C} 2 \mathrm{H} 2-\mathrm{ZFP}$ genes are closely related to abiotic stress. This study provides results on MsZFP genes, their response to various abiotic stresses, and new information on the $\mathrm{C} 2 \mathrm{H} 2$ family in alfalfa.
\end{abstract}

Keywords: alfalfa; Q-type $\mathrm{C} 2 \mathrm{H} 2$ zinc finger protein family; phylogenetic analysis; abiotic stress; expression pattern

\section{Introduction}

Zinc finger proteins (ZFPs) are one of the largest families of transcription regulators, with a highly conserved domain; they play crucial roles in plant development and abiotic stress responses in natural plants [1]. According to their different residues, zinc finger proteins are divided into several types, including $\mathrm{C} 2 \mathrm{H} 2, \mathrm{C} 2 \mathrm{HC}, \mathrm{C} 2 \mathrm{HC} 5$, and other [2]. Among these types, C2H2 ZFPs are the most numerous in eukaryotes [3]; they contain two cysteine (Cys2) and two histidine (His2) residues. In order to ensure the stability of their three-dimensional structure, a zinc ion is coordinated by Cys2/His2 (C2H2) with a $\beta \beta \alpha$ fold [4].

The Q-type ZFPs are a subfamily of the C2H2 ZFPs with a conserved "QALGGH" motif at the region of the zinc finger domain within the Cys2 and His2 residues; they participate widely in biological processes, and are endemic to plants with C2H2 ZFPs [5-7]. According to a previous study, the first C2H2-ZFP was found in Petunia, and 21 Q-type ZFPs were identified according to their special structure, which plays important roles in the activity of DNA binding [8]. More Q-type ZFPs have been observed in plants such as Arabidopsis, wheat (Triticum aestivum), and potato (Solanum tuberosum) [1,9,10]. All these 
Q-type ZFPs play vital roles in flowering time, leaf development and other biological processes, as well as response to abiotic stress [11]. For example, overexpression of ZFP36, an abscisic acid (ABA)-positive gene, increased tolerance to water stress and reduced competition for antioxidant enzymes in the ZFP36 mutant, and was induced by ABA signalling in rice [12]. In transgenic Arabidopsis, GmZF1 enhances tolerance during cold stress [13]. TaZFP1 plays vital roles in mediating salt stress tolerance by affecting other physiological processes [14]. The ZFP182 genes in rice participate in ABA-induced abiotic stress responses [15]. In addition, the overexpression of STZa in Arabidopsis displayed drought tolerance [7]. Therefore, the C2H2-ZFP gene family plays important roles in improving abiotic stress resistance in plants. Nevertheless, little research has been carried out on Q-type C2H2-ZFPs in alfalfa.

Alfalfa (Medicago sativa subsp. sativa) is one of the most economically valuable plants in the world, with high nutritional value and strong adaptability [16], famous as the "king of herbages" and widely planted in the northern area of China. However, adverse growth environments such as low temperatures, water deficit, and salinization of soil affect alfalfa survival and growth, restricting yield in the entire area. Therefore, in Northern China it is critical to cultivate and select alfalfa germplasm with stress resistance to enable better development of animal husbandry.

In the current study, we identified 58 Q-type $C 2 H 2$-ZFP members in alfalfa. The phylogenetic relationships, genomic location, gene structure, chromosome distribution, gene duplication and cis-regulatory elements were also explored. In addition, we analyzed the expression profiles of MsZFPs in various tissues and under abiotic stress. These results will provide a valuable resource in exploring the Q-type $\mathrm{C} 2 \mathrm{H} 2$ gene family and understanding the roles of the MsZFP gene family in alfalfa, especially the functional characterization of plant development processes and abiotic responses.

\section{Materials and Methods}

\subsection{Database Sources and Identification of the $\mathrm{C} 2 \mathrm{H} 2$ Gene Family in Alfalfa}

We downloaded 211 Arabidopsis C2H2 ZFP sequences from The Arabidopsis Information Resource (TAIR) (http:/ / www.arabidopsis.org, 25 May 2021) and 218 C2H2-ZFP sequences of $M$. truncatula from a published article [17]. All these plant $\mathrm{C} 2 \mathrm{H} 2$ protein sequences were queries to search the alfalfa $\mathrm{C} 2 \mathrm{H} 2$ family through local protein blast (BLASTP) against the whole genome sequence database [18], with an E-value threshold of 0.00001. In addition, redundant protein sequences were removed using the CD-Hit website (www.bioinformatics.org, accessed on 25 May 2021) with the default parameters [19]. The remaining $\mathrm{C} 2 \mathrm{H} 2$ sequences were confirmed by Pfam (www.pfam.xfam.org, accessed on 27 May 2021) and SMART (http:/ / smart.embl-heidelberg.de/, accessed on 16 June 2021), then Q-type C2H2-ZFP members were selected [20,21]. Subsequently, the ProtParam Tool (https: / /web.expasy.org/protparam/, accessed on 17 June 2021) was used to infer the index values of the grand average of hydropathicity (GRAVY) and the theoretical isoelectric point (pI) of these putative MsZFP genes [22]. Finally, we used the WoLF-PSORT (https: / / www.genscript. com/wolf-psort.html, accessed on 25 June 2021) to predict the subcellular localization of MsZFP [23].

\subsection{Analysis of Phylogenetic, Gene Structure and Conserved Composition MsZFP Genes}

To clarify the evolutionary relationship of these MsZFP genes, Clustal W software was used to align these MsZFP sequences with initial parameters [24], and MEGA 6.0 was used to construct a phylogenetic tree with the neighbour joining (NJ) method and 1000 replicate bootstrap tests [25]. The MsZFP gene structures were explored from the Gene Structure Display Server (www.gsgd.gao-lab.org, accessed on 17 July 2021). MEME v5.1.1 (http:/ / meme-suite.org/index.html, accessed on 26 July 2021) was used to estimate their conserved motifs [26]. The selected number of motifs was determined according to a previous study [27], and the default settings were used for the other parameters. 


\subsection{Analysis of Chromosomal Distribution and Gene Duplication}

Based on MapChart software, we were able to recognize the genomic mapping of MsZFP genes and their relative distances according to the genome annotation data of alfalfa. Gene duplication is a major source for expanding gene families and producing new genes in eukaryotes. To explore the gene duplication events of 58 MsZFP genes, we used TBtools software to perform a collinearity analysis [28]. In addition, Dnasp5 software was used to analyse the nonsynonymous (Ka) and synonymous (Ks) replacement rates of genes after replication, and to explore the mechanism of gene differentiation after replication [29,30].

\subsection{Cis-Regulatory Element Analysis}

The PlantCARE database (http:/ / bioinformatics.psb.ugent.be/webtools/plantcare/ $\mathrm{html} /$, accessed on 7 November 2021) was used to identify the cis-regulation of the changed MsZFPs under abiotic stresses, according to the sequences of $2000 \mathrm{bp}$ from the promoter region of MsZFP genes. We explored ten cis-regulatory elements related to stress, hormones, and light response, including ABRE (ABA-responsive element), ARE (antioxidant response element), CGTCA motif, DRE (dehydration responsive element), G-box, MBS (MYB binding site), LTR (low-temperature responsiveness), TC-rich repeats, TCA element, and TGACG motif. All these are involved in abscisic acid response, anaerobic induction, MeJA response, abiotic stresses, light response, drought inducibility, cold response, defence against stress, and salicylic acid response [31].

\subsection{Tissue Specific Expression of MsZFP Genes}

Based on the expression profiles of these MsZFP genes in specific tissues, we were able to speculate on their roles in alfalfa tissue development. Furthermore, the expression profiles of MsZFP genes in various tissues were explored by genome-wide transcriptome data downloaded from the CADL-Gene Expression Atlas, released by the Noble Research Atlas (https: / / www.alfalfatoolbox.org, accessed on 28 May 2021) for a total of six tissues of transcriptome data, including leaves, flowers, pre-elongated stems, elongated stems, roots and nodules. Subsequently, TBtools software was used to generate a heatmap of MsZFP gene expression data.

\subsection{Analysis of These MsZFP Genes under Abiotic Stress}

Four transcriptome sequencing projects were performed in previous studies, including cold stress (SRR7091780-SRR7091794) [32], drought, salt stress and ABA treatments (SRR7160313-SRR7160357) [33,34]. In this research, the expression of MsZFP genes was obtained through local protein blast (BLASTP) against these four transcriptomes, using TBtools software to generate heatmaps.

\subsection{Plant Materials and Stress Treatments}

The cultivated variety of XinjiangDaYe alfalfa was used as experimental material and cultivated by a hydroponic experiment in an artificial chamber. To ensure consistency of germination, seeds were vernalized under $4{ }^{\circ} \mathrm{C}$ conditions. After three days of germination, these seedlings were moved into specific nutritional conditions $(1 / 2 \mathrm{MS}, \mathrm{pH}=5.8)$ and cultivated under long-day conditions. Until the third leaf appeared, the plants were placed under different stress treatments (approximately 13 days after vernalization). For cold stress, these seedlings were cultivated in an artificial climate chamber with a $16 \mathrm{~h} \mathrm{light} / 8 \mathrm{~h}$ dark cycle at $4{ }^{\circ} \mathrm{C}$. Four treatment time points $(2,6,24$, and $48 \mathrm{~h})$ were sampled and used as a control. For drought and salt stress, these seedlings were put into specific nutritional conditions with $400 \mathrm{mM}$ mannitol and $250 \mathrm{mM} \mathrm{NaCl}$, respectively, and cultivated under a $16 \mathrm{~h}$ light $/ 8 \mathrm{~h}$ dark cycle at $22{ }^{\circ} \mathrm{C}$. A total of eight treatment time points were used $(1,3$, $6,12,24 \mathrm{~h}$, abiotic stress removal 1 and $12 \mathrm{~h}$ ), along with CK ("CK" indicates $0 \mathrm{~h}$ ). Under ABA stress, the seedlings were moved to a specific nutritional condition with $10 \mu \mathrm{M} \mathrm{ABA}$, and a total of four time points were sampled (CK, 1, 3, and $12 \mathrm{~h}$ ). Furthermore, the whole seedling was harvested under a cold environment, and the root tip was harvested for 
the ABA, drought, and salt treatments. Every sample contained six seedlings, and these samples were quick-frozen in liquid nitrogen and stored at $-80^{\circ} \mathrm{C}$.

\subsection{Quantitative Real-Time PCR Analysis}

A total of nine MsZFPs were selected as candidates for abiotic resistance genes. With reference to the manufacturer's instructions, the TRIzol method (Sangon Biotech, Shanghai, China) was used to extract the total RNA, in which cold stress RNA was extracted from the whole seedling and the other three stresses (ABA, drought, and salt) were extracted from the root tips of alfalfa. These RNAs were reverse-transcribed into single-stranded cDNAs according to the manufacturer's protocol using the FastKing RT Kit with gDNase (Tiangen Biotech, Beijing, China). Subsequently, a NanoDrop ND1000 spectrophotometer (Thermo Scientific, Waltham, MA, USA) was used to determine the concentration of each sample. qRT-PCR was performed on all of the selected genes with the CFX96TM Real-Time PCR Detection System (Bio-Rad, Los Angeles, USA). Every $10 \mu \mathrm{L}$ reaction volume consisted of $5 \mu \mathrm{L}$ of $2 \times$ SG Fast qPCR Master Mix, $1 \mu \mathrm{L}$ of cDNA, $1 \mu \mathrm{L}$ of DNF buffer, $0.2 \mu \mathrm{L}$ of each of the forward and reverse primer at $10 \mu \mathrm{M}$, and $2.6 \mu \mathrm{L}$ of sterilized $\mathrm{dd}_{2} \mathrm{O}$. The reaction process was set as follows: denaturation $\left(95^{\circ} \mathrm{C} / 30 \mathrm{~s}\right)$ and 40 cycles at $95^{\circ} \mathrm{C} / 5 \mathrm{~s}$ and $60{ }^{\circ} \mathrm{C} / 30 \mathrm{~s}$. Every reaction consisted of three replicates, and according to the expression of the Medicago actin gene (AA660796) [35], the relative expression level of MsZFP genes was normalized with the $2^{-\Delta \Delta C q}$ method. According to the genome data of XinjiangDaYe alfalfa, all MsZFP gene primer pairs were designed using Primer 6 software; the lengths of the PCR products are listed in Table S1.

\section{Results}

\subsection{Identification and Physicochemical Properties of MsZFPs}

A total of 58 MsZFP genes were obtained from the alfalfa genome after screening domains and removing redundant genes, and MsZFP01 was rewritten to MsZFP58 based on the order of occurrence of the genome data (Table S2). In addition, the quantity of amino acids, molecular weight (MW), pI, GRAVY and subcellular localization of these MsZFP proteins were analysed (Table S3). These 58 putative MsZFP proteins ranged from 126 (MsZFP14) to 1633 amino acids (AA) (MsZFP40) in length. The MWs of these proteins were varied from $14000.01 \mathrm{Da}$ in MsZFP14 to $184189.9 \mathrm{Da}$ in MsZFP40, and their predicted pI ranged from 4.83 (MsZFP31) to 10.03 (MsZFP06). In addition, the GRAVY of all MsZFP proteins were negative ( $<0)$, varying from -1.194 (MsZFP106) to -0.169 (MsZFP40), suggesting that they were soluble hydrophilic proteins. Moreover, all these Q-type ZFPs were nuclear-localized according to the results of subcellular localization analysis.

\subsection{Phylogenetic Analysis of the Selected MsZFPs}

To clearly explore evolutionary relationships, a phylogenetic tree was constructed with 58 Q-type MsZFPs and 58 Arabidopsis ZFPs (Table S4) by MEGA6 with the NJ method. All these MsZFPs were grouped into three different groups (Figure 1). Furthermore, these alfalfa MsZFPs were closely clustered with Arabidopsis ZFPs (Figure 1), and many of the functions of these Arabidopsis ZFPs were known, suggesting that some of these alfalfa gene functions could be inferred according to Arabidopsis. Based on clades and bootstrapping, the resulting phylogenetic trees were divided into twelve subclasses, including C1-I to IV, C2-I to III, and C3-I to V. According to these results, the same phylogenetic clades may represent the most intimate homologous gene pair of alfalfa and Arabidopsis. In addition, 58 MsZFPs were divided into different groups. Groups C1, C2, and C3 possessed 16, 6, and 36 MsZFPs, respectively. Furthermore, the main clades, C1 and C3, had 4 and 5 subclasses, respectively. 


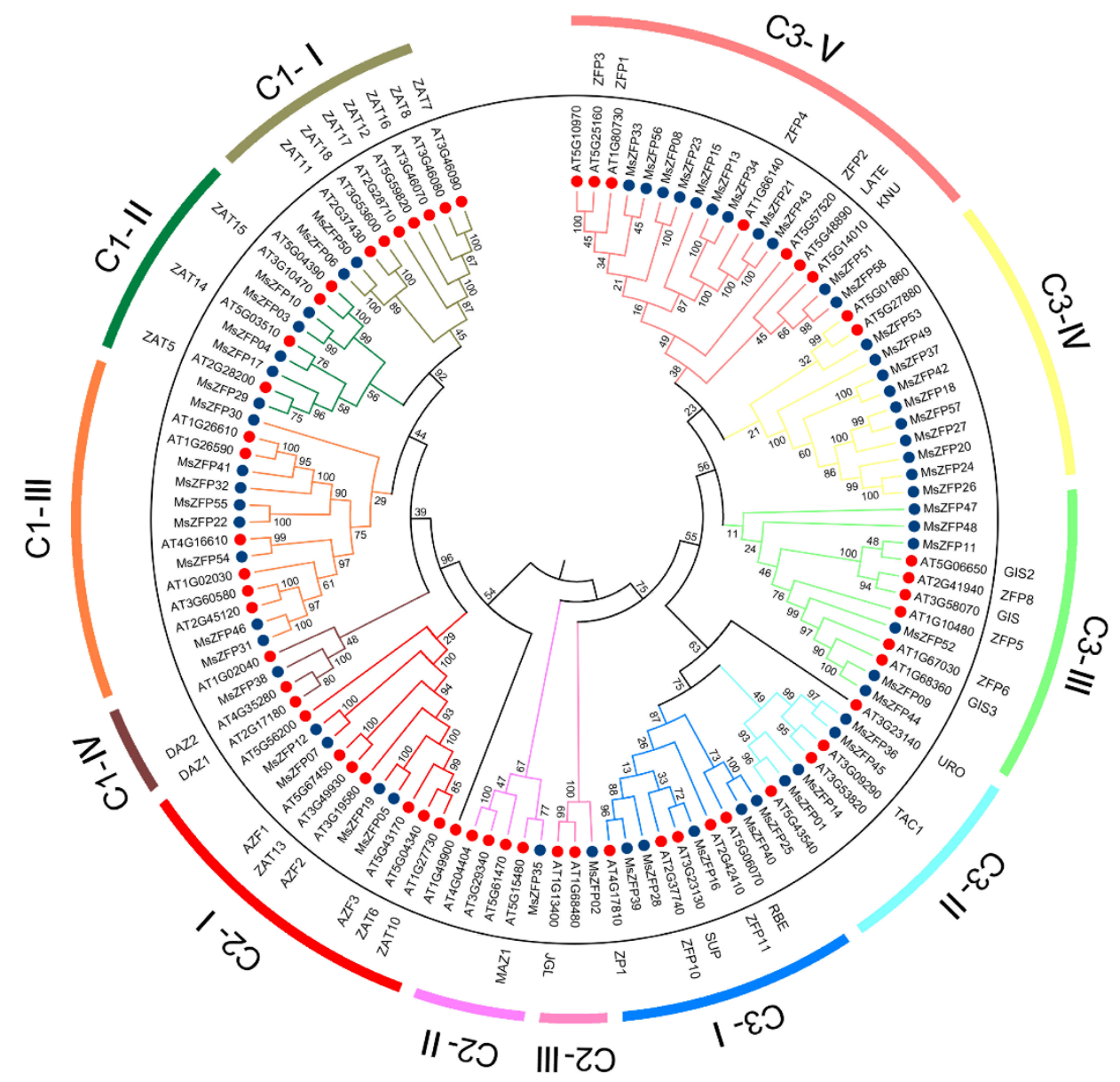

Figure 1. Phylogenetic analysis of Q-type MsZFPs; the phylogenetic tree was created using the MEGA 6.0 program (bootstrap value set at 1000 with neighbour-joining). The phylogenetic tree represents the relationship between 58 Q-type $C 2 \mathrm{H} 2-\mathrm{ZFP}$ genes of alfalfa and 58 Q-type $\mathrm{C} 2 \mathrm{H} 2$-ZFP genes of Arabidopsis. All C2H2-ZFP genes were clustered into five clades and twelve groups, distinguished here by different colours.

\subsection{Gene Structure and Motif Composition Analysis of the MsZFPs}

We could predict the evolutionary process by analysing the gene structures. To better understand the structural diversity of MsZFPs, we analysed the number of exon and intron structures of all MsZFPs (Figure 2B). The results showed that the number of introns varied from zero to four. According to the number of introns, $50 \mathrm{MsZFPs}(86.20 \%)$ were intronless, six MsZFPs had one intron (10.34\%), and the other two MsZFP genes contained at least three introns.

We identified ten conserved motifs in MsZFPs with the MEME tool, with variable lengths from 8 to 36 amino acids (Figure 2C, Table S5). Among these motifs, motif 1 was widely discovered in all MsZFPs except MsZFP41 and MsZFP54, matching up with the Cys$\mathrm{X} 2$-Cys-X12-His-X3-His single structure. Interestingly, motif 5 was present at the C-terminal region of all the MsZFPs except MsZFP13, which is the most dominant transcriptional repression motif in plants [10]. Moreover, some motifs were specific to specific groups. For example, motifs 2 and 10 existed only in Group C1. Motifs 4, 8, and 9 were unique to clade C3-III. 


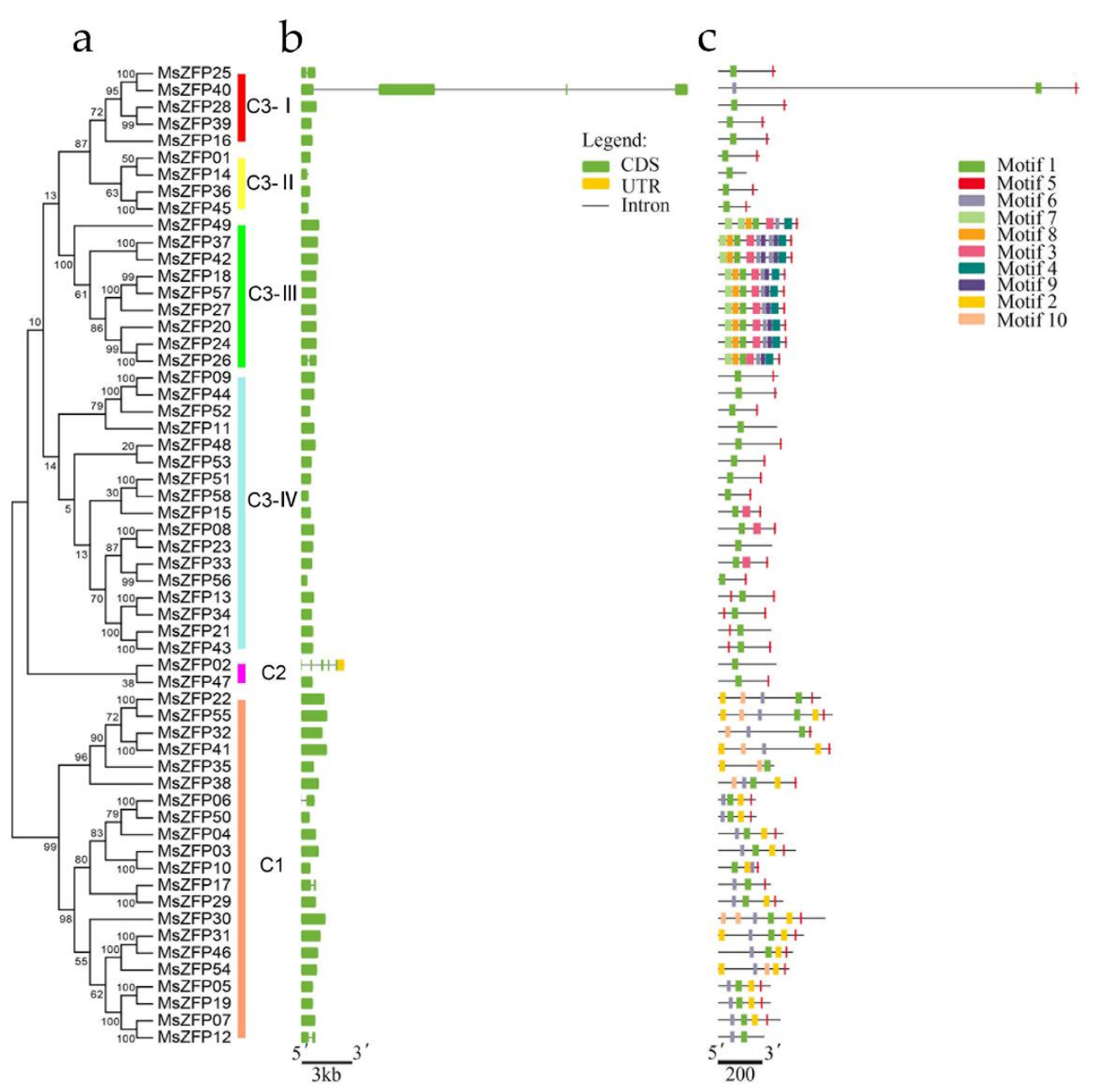

Figure 2. Phylogenetic relationship, gene structure, and motif compositions of alfalfa Q-type C2H2ZF genes. The phylogenetic tree was constructed using MEGA 6.0 with the neighbour-joining method. (a) Multiple alignments of 58 protein sequences of alfalfa MsZFPs executed by ClustalW. (b) Exon/intron structures of alfalfa $\mathrm{C} 2 \mathrm{H} 2-\mathrm{ZFP}$ genes. Exon/intron structures were analyzed by the Gene Structure Display Server. Exons/introns of each subgroup are represented by green boxes and black lines, respectively. (c) Schematic representation of the conserved motifs, as identified by MEME; each coloured box represents a motif.

\subsection{Chromosomal Distributions and Gene Duplications in MsZFPS}

Based on the alfalfa genome data and chromosomal (Chr.) annotation, all MsZFP genes were unevenly distributed on $22 \mathrm{Chr}$. except MsZFP58, which was located on unmapped scaffolds. There were no MsZFPs located on Chr. 6. As shown in Figure 3, a total of ten MsZFPs were located on Chr. 1.2, which had the largest number of MsZFPs. Only one MsZFP gene was distributed on chromosomes 1.3, 2.1, 2.3, 3.2, 4.4, and 7.1. In addition, there were two MsZFP genes located on chromosomes 1.1, 1.4, 4.2, 5.2, 7.3, 8.2, and chromosome 8.3. Three MsZFPs were located on chromosomes 3.1, 3.3, 3.4, 4.1, 4.3, 5.3, and chromosome 5.4 . 


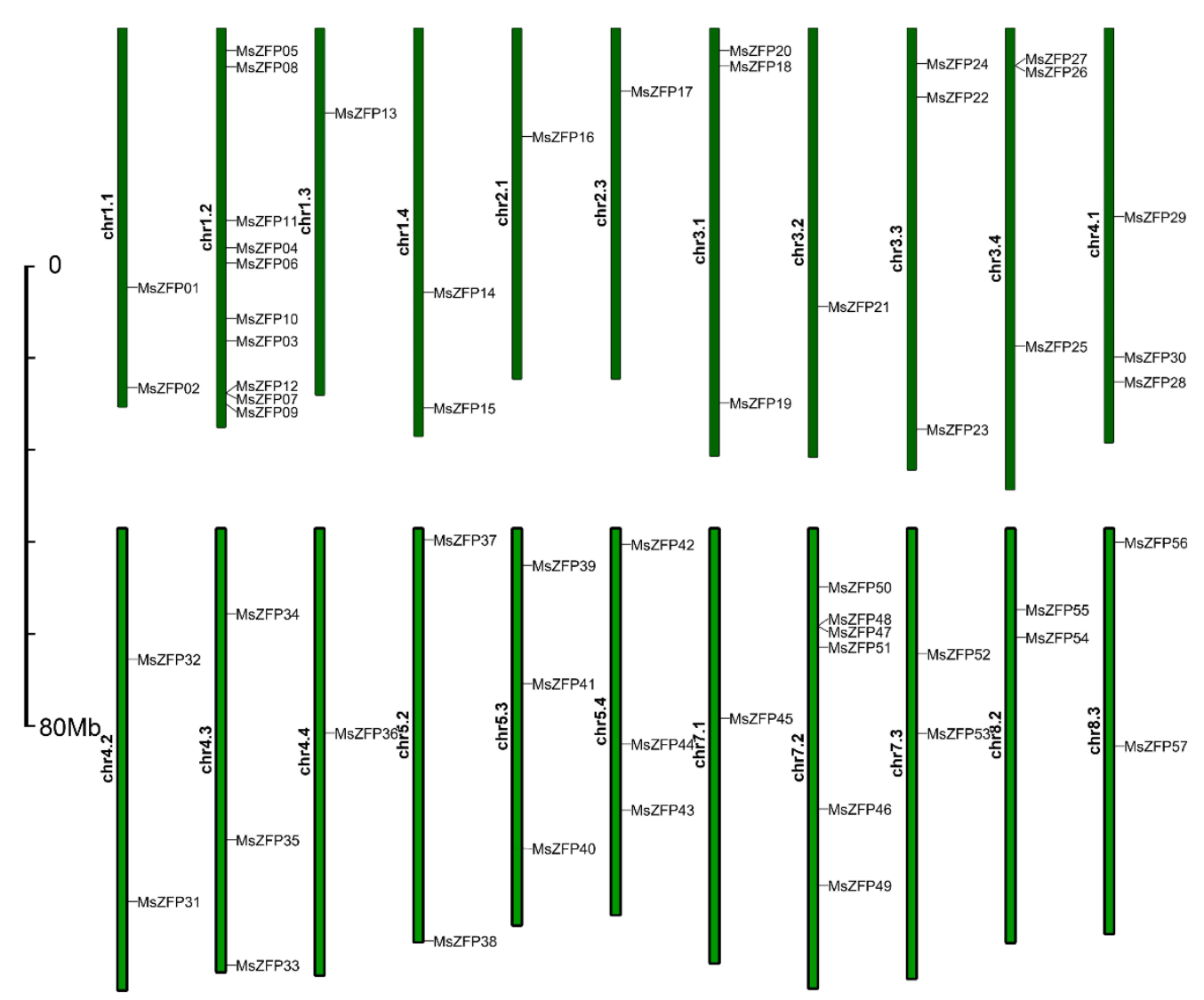

Figure 3. Genomic distributions of $58 \mathrm{MsZFP}$ genes across the 32 alfalfa chromosomes. In the "MsZFP gene distribution map" of 22 alfalfa chromosomes, the green bars represent each chromosome, and the black lines indicate the position of each MsZFP gene.

According to the duplication events of the MsZFP gene family, we can analyse the MsZFP gene duplication event in alfalfa. The substitution rate of non-synonymous (Ka) and synonymous (Ks) is the basis for assessing the selection pressure of duplication events. $\mathrm{A} \mathrm{Ka} / \mathrm{Ks}$ value of $1,<1$, or $>1$ indicates neutral selection, purification selection, and positive selection, respectively. [10]. TBtools was used to visualize the collinearity relationship between these MsZFPs in alfalfa. In this research, a total of ten pairs of MsZFP genes (16/58, $27.59 \%$ ) were confirmed as segmental duplications, which were randomly distributed on twelve chromosomes (Figure 4, Table S6). The Ka/Ks of duplicated MsZFPs varied from 0.2482 to 0.9344 , which means that these synteny genes evolved under purifying selection.

To better understand the evolutionary relationship of these MsZFP genes, we selected two model plants, Arabidopsis and M. truncatula, in order to analyse their synteny relationship. In our research, we identified 29 pairs of orthologues between Arabidopsis and M. sativa (Figure 5A and Table S7), and the ratio of Ka/Ks varied from 0.1170 to 1.4973 . In addition, we identified 42 pairs of orthologues between $M$. sativa and $M$. truncatula with synteny relationships (Figure 5B, Table S8); the ratio of Ka/Ks varied from 0.0453 to 2.4149 . Furthermore, comparing the above results, it is easy to conclude that the M. sativa genes have higher similarity with $M$. truncatula. 


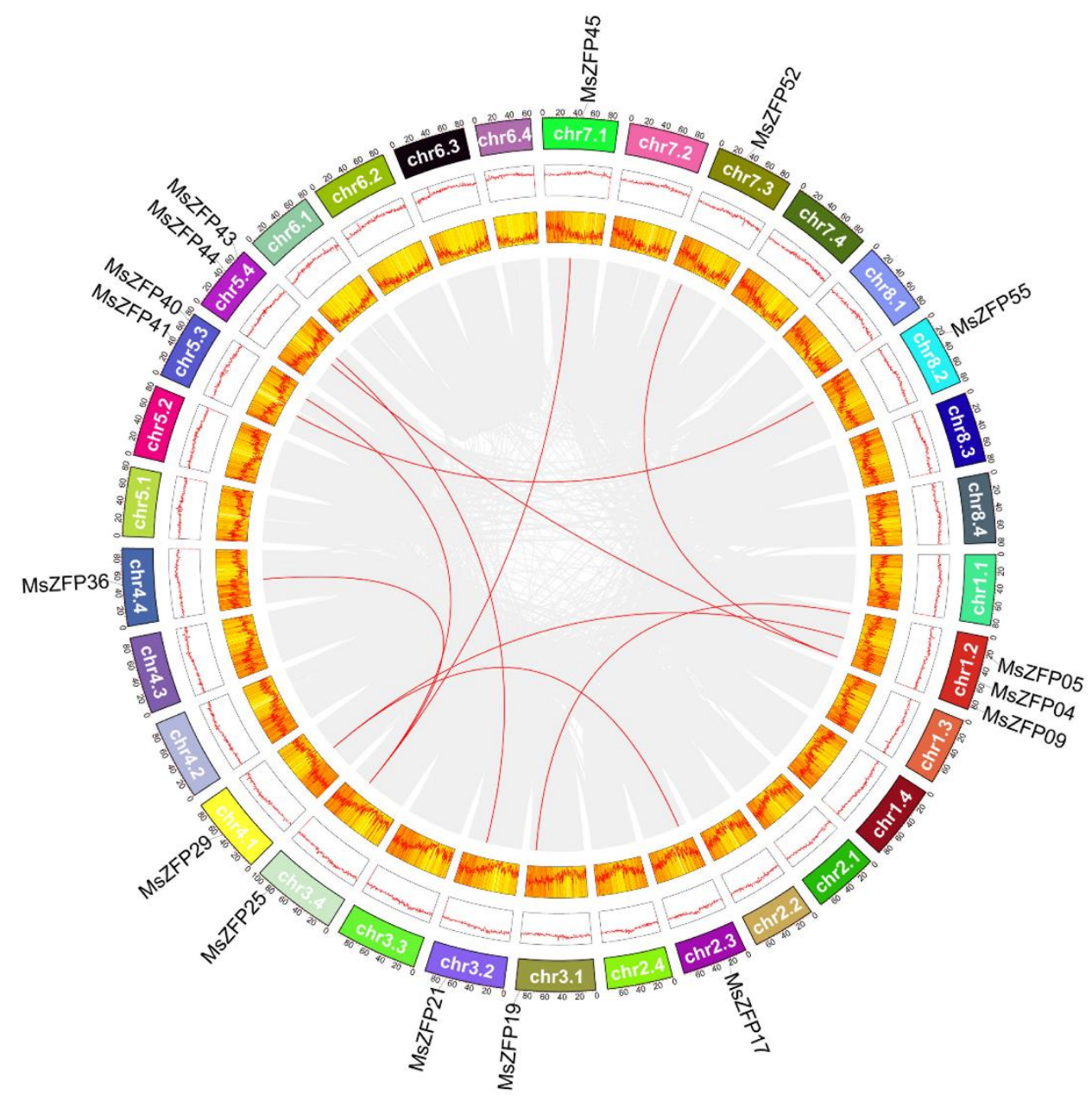

Figure 4. Synteny analysis of MsZFP genes in alfalfa. Grey lines represent all synteny blocks in the alfalfa genome. Red lines indicate the duplicated MsZFP gene pairs in alfalfa. Yellow and red boxes indicate the gene density and GC content of all genes in alfalfa, respectively.
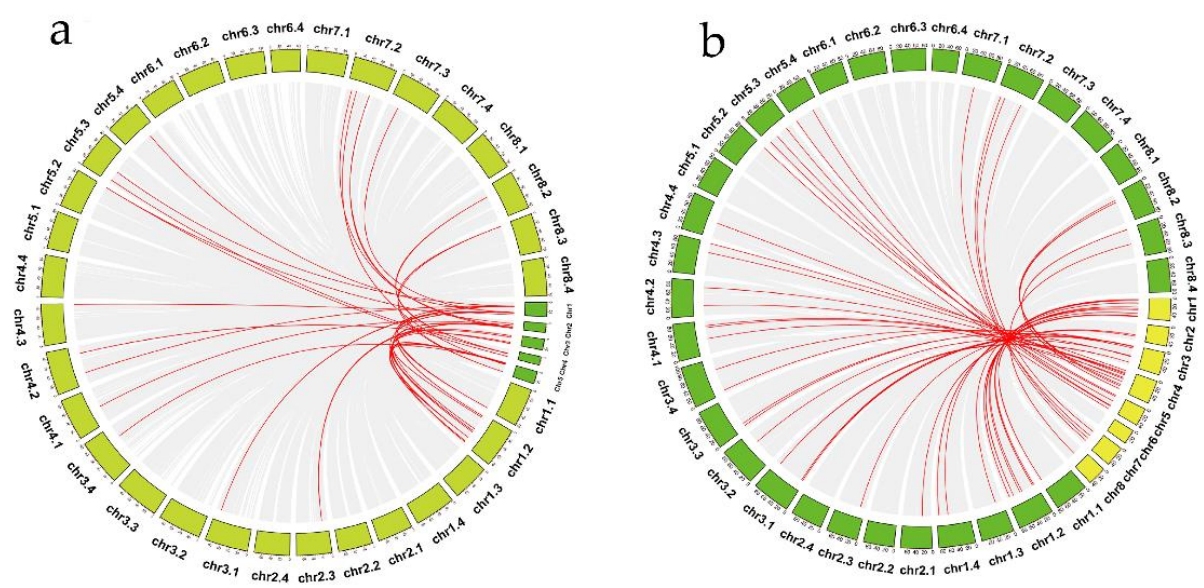

Figure 5. Synteny analysis of MsZFP genes with (a) Arabidopsis and (b) Medicago truncatula. The red line represents gene pairs that are homologous.

\subsection{Analysis of MsZFP Gene Promoter Cis-Regulatory Elements}

Cis-regulatory elements can regulate transcription for precise initiation and efficiency of genes by binding to transcription factors. Therefore, we explored the composition of ten cis-regulatory elements (ABREs, AREs, CGTCA motifs, DREs, G-boxes, TGACG motifs, 
MBSs, LTRs, TC-rich repeats, and TCA elements) in the promoter regions of the 58 induced MsZFPs under abiotic stress (Figure S1, Table S9). This study aimed to systematically analyse these regulatory elements, aiming to be assist in the discovery of antistress genes. AREs had the largest number of cis-regulatory elements, with 140. However, the DREs only had two cis-regulatory elements in these MsZFPs. In addition, according to Figure S2, we found that only MsZFP11 had nine cis-regulatory elements, while MsZFP58 did not contain any of these ten cis-regulatory elements.

\subsection{Expression Patterns of the MsZFPs in Different Tissues}

Tissue-specific expression is usually related to the specular function of MsZFP genes in alfalfa. According to the downloaded alfalfa B47 genotype expression database, we evaluated the transcript abundance pattern of the MsZFP-encoding genes in a total of six different tissues: leaf, flower, pre-elongated stem, elongated stem, root, and nodule; 42 MsZFP genes were detected in the database. A heatmap was then constructed to visualize these expression patterns with TBtools. According to their expression patterns, $42 \mathrm{MsZFPs}$ were clustered into six clades, named A to F (Figure 6). Cluster A contained three genes, which displayed the highest expression level in root tissues. Additionally, subgroups $\mathrm{C}, \mathrm{D}$, and $\mathrm{E}$ showed high expression levels in root, nodule, and flower tissues, respectively. Clade B included four genes that exhibited variable expression profiles in these six tissues. In contrast, subclade F showe no expression in the six plant tissues.

\subsection{Expression Analysis of the MsZFPs in Abiotic Stress}

To probe the transcript abundance of MsZFP genes under cold, drought, salt and ABA stress, we used BLASTP against transcriptome datasets constructed by our laboratory. A total of 57 MsZFPs were induced under four stresses; these expression patterns are displayed in Figures S2-S5. For the cold treatment, all 57 induced MsZFPs were divided into seven groups based on their expression pattern at five time points. The expression of Group $\mathrm{C}$ was highly upregulated at $0-2 \mathrm{~h}$ and rapidly declined at the subsequent time points. In contrast, clade $\mathrm{F}$ displayed the opposite results, in which expression levels were severely downregulated at $0-2 \mathrm{~h}$ and remained relatively stable. Interestingly, subgroup E displayed light expression levels at $2 \mathrm{~h}$ and gradually peaked at $24 \mathrm{~h}$. Groups A, B, and D MsZFPs showed variable expression profiles at all five time points. Group $\mathrm{G}$ showed no expression at any time under cold stress.

For the ABA treatment, all the induced genes were divided into seven categories. Group A was severely and continually downregulated with the extension of treatment. Genes of Groups B and D were highly upregulated at $3 \mathrm{~h}$ and were inhibited or unexpressed at other time points. Group $C$ revealed variable expression levels at four time points. The expression levels of clades E, F, and G were slightly upregulated at $3 \mathrm{~h}$ and reached their maximum values at $12 \mathrm{~h}$.

Under drought treatment, all these genes were induced at different levels. According to Figure S4, Group A exhibited a process of upregulation and reached its maximum level after drought removal $24 \mathrm{~h}$. The expression levels of Groups $\mathrm{C}$ and D fluctuated after treatment and were higher after rehydration than before treatment. Groups $\mathrm{E}$ and $\mathrm{G}$ were upregulated at the beginning of treatment at $1 \mathrm{~h}$ and $24 \mathrm{~h}$, respectively, and gradually downregulated with the extent of processing time, suggesting that the genes of Group E can more rapidly respond to drought stress than the genes of Group G. The expression profile of clade $\mathrm{F}$ gradually decreased under the treatment of drought stress from 1 to $24 \mathrm{~h}$, and reached its minimum level after drought removal $12 \mathrm{~h}$, suggesting positive regulation. 


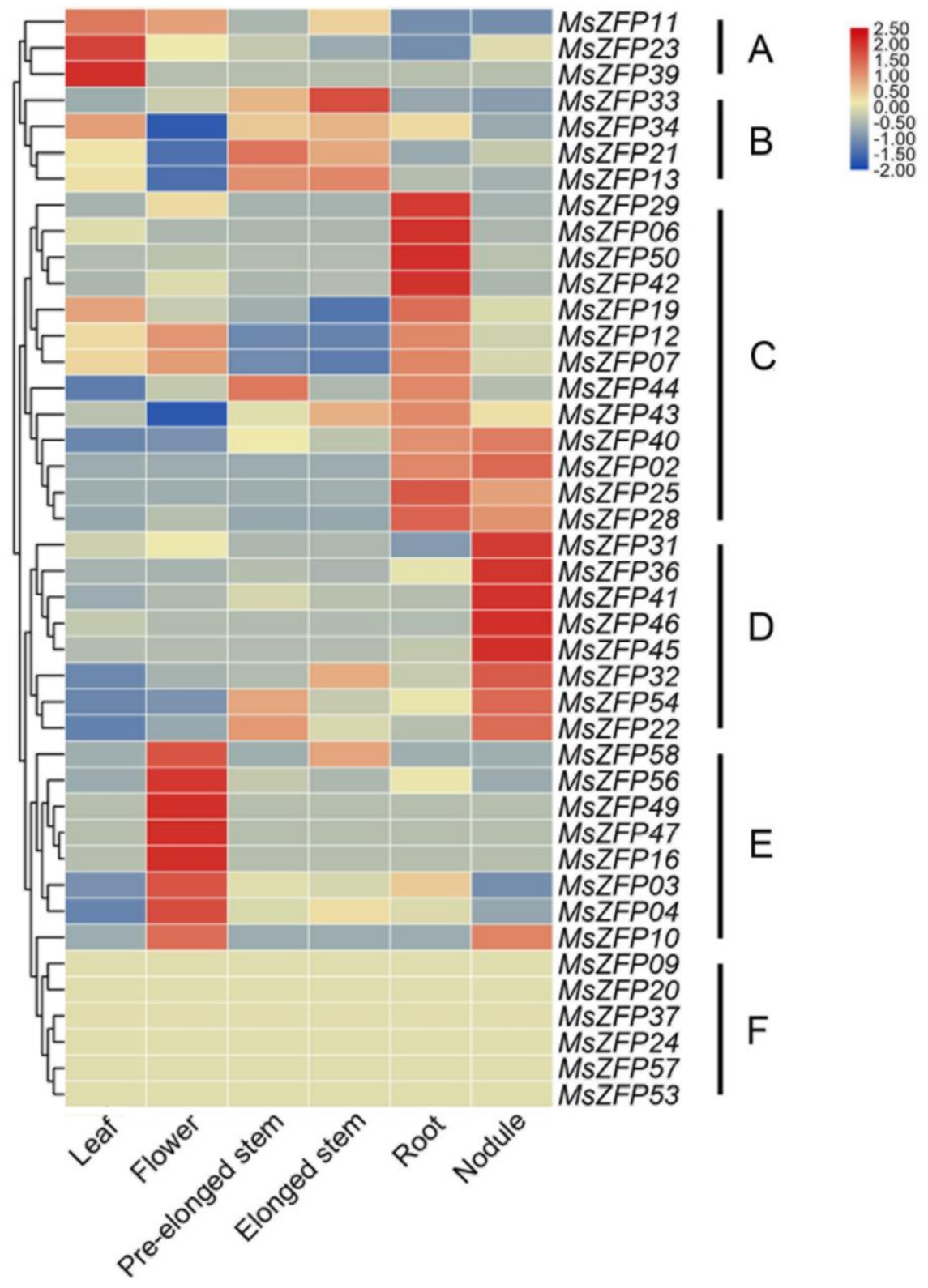

Figure 6. Heatmap representation of the expression patterns of MsZFPs among different tissues. Lower and higher levels of transcript accumulation are indicated by red and blue, respectively, and the median level is indicated by light yellow. Microarray data were downloaded from the CADL-Gene Expression Atlas database, and the heatmap was constructed using TBtools. Subgroups A to $\mathrm{F}$ displayed the highest transcript accumulation level in different tissues.

According to Figure S5, it is not difficult to speculate that all 57 MsZFPs were positive to salt stress, with variable expression levels. The expression of Group A exhibited a dynamic change before removal of salt stress for $12 \mathrm{~h}$ and suddenly reached a peak. In addition, the genes of subgroup B were highly sensitive to salt stress and rapidly reduced after treatment for $1 \mathrm{~h}$. Group $\mathrm{C}$ reached its maximum minimum level at $3 \mathrm{~h}$ and $12 \mathrm{~h}$ after removal, respectively. Similar to Group C, Group D reached these two peak values at $6 \mathrm{~h}$ and $12 \mathrm{~h}$ after removal, respectively. Group D displayed a negative response to salt stress, with the expression level not significantly upregulated until treatment for $6 \mathrm{~h}$, and rapidly reduced after stress removal. Groups F and G were highly sensitive to salt stress; however, their expression levels did not change significantly after stress treatment. 


\subsection{Validation of $q R T-P C R$}

Using the RNA-seq data on abiotic stress, qRT-PCR was performed to validate the nine MsZFPs that were significantly induced (Figures S3-S7), under drought, salt stress and ABA treatment; their primer sequences for qRT-PCR are listed in Table S1. Based on the qRT-PCR analysis, the selected MsZFP genes were induced to varying degrees by different stresses. Notably, most of these MsZFP genes were significantly upregulated under all abiotic stresses, suggesting positive regulation. At the same time, the expression trend of the selected Q-type $\mathrm{C} 2 \mathrm{H} 2$ genes was consistent with the RNA-seq analysis results. For example, MsZFP19, and MsZFP51, whose expression levels were rapidly upregulated with time under ABA treatment, showed results similar to the RNA-seq data (Figure 7). Interestingly, the variation trend of the expression of MsZFP41 under ABA treatment initially decreased and then increased, which was different from the variation trend of the expression of MsZFP41 under drought treatment.
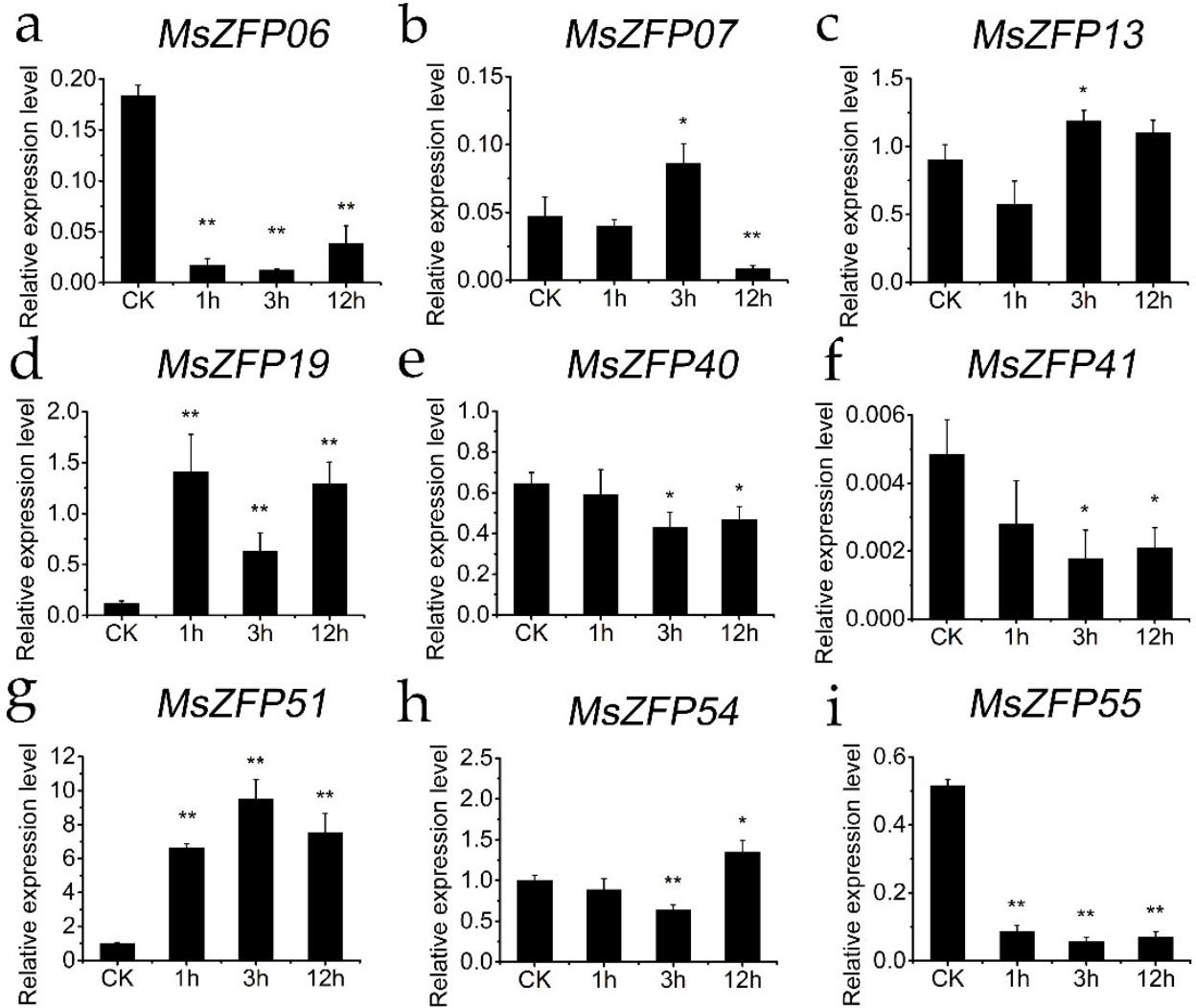

Figure 7. Expression analysis of nine MsZFP genes under ABA treatment, revealed by qRT-PCR. Values represent the average $\pm \mathrm{SD}$ of root tips. Error bars represent the standard errors of the means $(n=3)$. The relative expression level was normalized according to the values in the control $(0 \mathrm{~h})$. And a to i means the results of qRT-PCR of selected MsZFPs "*" indicates significance at the 0.05 level, and "**" indicates significance at the 0.01 level.

\section{Discussion}

Q-Type ZFPs are a subfamily of C2H2-ZFPs, which play crucial roles in plant response to abiotic stress. Previous studies have identified many Q-type C2H2 ZFPs in plants such as Arabidopsis, rice, wheat, poplar, and potato [9,10,36-38]. However, there have been few studies on the molecular function of MsZFPs under abiotic stress conditions in alfalfa. Therefore, this research aimed to analyse this gene family in depth, hoping to be assist in the mining of antistress genes. In this research, we investigated the features of Q-type C2H2 ZFPs using previous studies of other plants; a total of 58 Q-type MsZFPs were identified through genome-wide identification. Then, the physical and chemical properties, gene structure, conserved motifs, phylogenetic relationships, chromosomal mapping, synteny 
analysis, cis-regulatory element composition, specific expression of tissues and expression pattern under abiotic stress were all investigated. The results provided significant and valuable information to aid in better exploring the evolutionary relationship and function of these MsZFPs.

In our research, 58 Q-type C2H2 ZFPs were identified in alfalfa, more than were identified in Triticum aestivum [39], but fewer than the number identified in potato [10] and rice [40]. The lengths of these protein sequences were between 126 and 1633 amino acids (Table S3). Phylogenetic analysis showed that 58 MsZFPs were divided into 12 groups, which were similar to StZFPs in Solanum tuberosum L. [10]. Moreover, some of the selected Arabidopsis Q-type C2H2 ZFP genes and the MsZFPs were clustered into the same clade, suggesting that they may have similar functions under abiotic stress and a close evolutionary relationship. Changes in their intron-exon numbers can affect the function of genes during evolution, and previous studies have shown that the fewer introns the genes possess, the easier the function of genes during environmental challenge [41]. In this study, all the MsZFPs were divided into six groups, and most of the MsZFPs were intron-less. In addition, motif 1 was widely distributed in MsZFPs. Notably, motif 5 was usually located at the end of these proteins, and among them, 56 (56/58, 96.55\%) MsZFP genes had at least the "LxLxL" type of EAR motif, suggesting that the MsZFPs are rich in potential transcriptional inhibitors. In addition, previous research has identified many transcriptional repressors in plants [42]. For example, the LATE FLOWERING (LATE) gene in Arabidopsis [43] and the KNUCKLES (KNU) [44], a transcriptional repressor of cellular proliferation in Arabidopsis, were clustered in the same subclade as MsZFP51 and 58, suggesting that these two MsZFPs have functions similar to transcriptional repressors.

Chromosomal mapping analysis showed that all Q-type MsZFP genes were dispersed on 22 chromosomes. In addition, all of the copies of chromosomes 1, 3, and 4 (M. sativa is an autotetraploid plant, and each chromosome has four copies) with Q-type MsZFPs were caused by its complex genetic background. Gene duplication events usually contribute to the emergence of members of gene families as new functions are produced in plant genome evolution [45]. In our study, a total of ten pairs of MsZFP genes $(16 / 58,27.59 \%)$ were identified as segmental duplications, and most syntenic MsZFPs were located in the middle of chromosomes. MsZFP25 is collinear with three genes, and all four genes are clustered in the $\mathrm{C} 3$ group, suggesting that they may have a similar origin. Therefore, it is important to investigate their duplication relationship in order to further research on the evolutionary relationship of this gene family.

Cis-regulatory elements are located upstream of genes and influence gene functions by binding with TFs. In the current study, the promoter regions of MsZFPs had many response elements, mainly hormone-related elements, light-related elements and stress response elements. Among these, AREs were most widely present in the MsZFPs, followed by ABREs and G-boxes. In addition, only MsZFP11 and MsZFP13 had DRE regulatory elements, while MsZFP58 did not have any cis-regulatory elements among the investigated regulatory elements. A previous study confirmed that many important cis-regulatory elements already existed in the promoter regions of stress response genes in MYBs, WRKYs, and MADS-boxes [35,40,46]. Furthermore, many of these elements, such as ABREs and DREs, have been reported to widely participate in abiotic stress responses in Artemisia annua, Arabidopsis and wheat [47-49]. However, no study has investigated these key regulatory elements in alfalfa. Therefore, according to these results, which provide many candidate genes for anti-abiotic stress, their specific functions need to be confirmed by further study.

Specific expression of MsZFP genes in different tissues could provide a clear study direction for plant growth development. Gene expression patterns can provide significant supportive data to better understand the function of MsZFPs. According to Figure 6, a total of $36 \mathrm{MsZFPs}$ were expressed in different tissues to variable degrees; each group displayed tissue-specific expression patterns, especially in Groups C, D and E, which showed higher expression levels in roots, nodules, and flowers, respectively. Therefore, we can speculate 
that these may become the key regulatory TFs in regulating plant growth and flowering According to these tissue-specific expression patterns, MsZFP genes widely participate in the process of growth development with the related tissue, which provides insight into how we can promote special tissue growth and development by changing the expression level of these MsZFPs using biotechnology.

Environmental stresses can affect the growth of plants and crop productivity [50]. A previous study explored many $\mathrm{C} 2 \mathrm{H} 2-\mathrm{ZFP \textrm {s }}$, which are widely related to abiotic stress responses, in various plants such as Arabidopsis [51], petunia [52], and potato [53]. For example, ZAT10 is a transcriptional repressor in Arabidopsis, and overexpression of ZAT10 can enhance the tolerance of plants to abiotic stress [54]. The expression level of StZFP1 in potato can be induced by salt stress, drought stress and exogenously applied ABA, and ectopic expression of StZFP1 in tobacco can increase tolerance to salt [53]. In Oryza sativa, ZFP179 has been implicated in plant development and stress responses induced by salt, drought, and ABA treatments at the seedling stage. Overexpression of ZFP179 in rice can increase salt tolerance and shows high sensitivity to exogenous ABA in seedlings [36]. In our study, a total of 57 MsZFP expression patterns were explored using RNA-Seq data previous obtained in our laboratory. Most of these MsZFPs were induced under different abiotic stresses. According to the expression profiles in Figures S2-S5, we found that MsZFP20, MsZFP26, MsZFP37, MsZFP42, MsZFP44, MsZFP51, and MsZFP58 were induced under $A B A$, salt, and drought stress. However, these genes were negatively associated with cold stress in alfalfa. In the current study, we verified the expression levels of nine MsZFPs under abiotic stress using qRT-PCR. However, some of the fold changes between the RNA-Seq data and qRT-PCR results were different, which was also found in prior research $[40,55,56]$ and may be caused by the difference in genetic diversity among alfalfa individuals, or by differences in sampling time [57]. In conclusion, the expression patterns of MsZFP genes under various abiotic stresses will provide many new candidate genes for further exploration of the mechanisms of resistance in alfalfa.

\section{Conclusions}

In the current research, we provided a comprehensive analysis of 58 Q-type $\mathrm{C} 2 \mathrm{H} 2-$ ZFPs in the alfalfa genome. These MsZFPs were divided into twelve groups, with most of the MsZFPs closely related to known antistress genes in Arabidopsis. We explored their physiochemical properties, phylogenetic relationships, gene structures, motif composition, and cis-regulatory elements. Chromosomal mapping and collinearity analysis revealed the duplication relationship of alfalfa MsZFPs. In addition, the tissue expression patterns showed that many of the MsZFPs were expressed in specific tissues at different levels. We selected nine candidate genes that were highly induced under abiotic stress and used qRT-PCR to validate their expression patterns. Our study contributes to understanding of the roles of MsZFP genes under abiotic stress and provides resources for further molecular and functional analysis in alfalfa. It may also contribute to the improvement of abiotic stress tolerance using molecular biology techniques such as RNA interference, overexpression, and CRISPR/Cas9 technology in future research.

Supplementary Materials: The following are available online at https:/ / www.mdpi.com/article/ 10.3390/genes12121906/s1, Additional file 1: Table S1. Information of the selected MsZFP primers used in quantitative real-Time PCR. Table S2. The putative 58 MsZFP protein sequences in Medicago sativa L. Table S3. Summary of the Q-type $\mathrm{C} 2 \mathrm{H} 2$ transcription factor gene in alfalfa. Table S4. The putative 58 Q-type C2H2 ZFP protein sequences in Arabidopsis thalia. Table S5. MEME motif sequences in predicted MsZFP proteins. Table S6. Ka/Ks ratios of the syntenic relationships between MsZFPs. Table S7. Ka/Ks ratios of the syntenic relationships between alfalfa and Arabidopsis. Table S8. Ka/Ks ratios of the syntenic relationships between alfalfa and Medicago truncatula. Table S9. The description of the selected cis-regulatory elements. Additional file 2: Figure S1. Analysis of cis-regulatory elements of the promoter regions of MsZFP genes of alfalfa. Figure S2. Expression of 57 MsZFP genes in response to cold treatment. Figure S3. Expression of $57 \mathrm{MsZFP}$ genes in response to ABA treatment. Figure S4. Expression of $57 \mathrm{MsZFP}$ genes in response to drought stress. Figure S5. Expression of 
57 MsZFP genes in response to salt stress. Figure S6. Expression analysis of nine genes under drought treatment, revealed by qRT-PCR. Figure S7. Expression analysis of nine MsZFP genes under salt treatment, revealed by qRT-PCR.

Author Contributions: Z.L. designed the study. J.P., M.L. and P.M. performed experiments. J.P., P.M. Q.Z. and W.L. analyzed the data. J.P. wrote the manuscript. Z.L. provided fund for this study. All authors have read and agreed to the published version of the manuscript.

Funding: This research was supported by the Strategic Priority Science and Technology Project of the Chinese Academy of Sciences (XDA26030103), the National Natural Science Foundation of China (31722055), Key Science and Technology Foundation of Gansu Province (19ZD2NA002), and the National Natural Science Foundation of China (32071862).

Institutional Review Board Statement: Not applicable.

Informed Consent Statement: Not applicable.

Data Availability Statement: The draft genome data of alfalfa was obtainedfrom https: / figshare. com/projects/whole_genome_sequencing_and_assembly_of_Medicago_sativa/66380, accessed on 23 May 2021. The Arabidopsis and M. truncatula $\mathrm{C} 2 \mathrm{H} 2$ protein sequences were downloaded from The Arabidopsis Information Resource (TAIR9) (www.arabidopsis.org, accessed on 26 May 2021) and the published article, respectively. Genome-wide transcriptome data of different alfalfa tissues were acquired from the CADL-Gene Expression Atlas (https: / www.alfalfatoolbox.org, accessed on 28 May 2021). All transcriptome sequencing data used in this study are available in NCBI SRA (https:/ / www.ncbi.nlm.nih.gov/sra/, accessed on 29 May 2021): SRR7091780-SRR7091794 (cold treatment) and SRR7160313-SRR7160357 (ABA, drought and salt treatments).

Acknowledgments: Not applicable.

Conflicts of Interest: The authors declare that there are no competing interests.

\section{References}

1. Englbrecht, C.C.; Schoof, H.; Böhm, S. Conservation, diversification and expansion of $\mathrm{C}_{2} \mathrm{H}_{2}$ zinc finger proteins in the Arabidopsis thaliana genome. BMC Genom. 2004, 5, 39. [CrossRef]

2. Michael, M.; Chrisopher, U. Recent developments in the engineering of zinc finger proteins. Brief. Funct. Genom. Proteomic 2003, 1, 342-355.

3. Ciftci-Yilmaz, S.; Mittler, R. The zinc finger network of plants. Cell Mol. Life Sci. 2008, 65, 1150-1160. [CrossRef]

4. Takatsuji, H. Zinc-finger proteins: The classical zinc finger emerges in contemporary plant science. Plant. Mol. Biol. 1999, 39, 1073-1078. [CrossRef]

5. Pabo, C.O.; Peisach, E.; Grant, R.A. Design and selection of novel Cys2His2 zinc finger proteins. Annu. Rev. Biochem. 2001, 70, 313-340. [CrossRef]

6. Agarwal, P.; Arora, R.; Ray, S.; Singh, A.K.; Singh, V.P.; Takatsuji, H.; Kapoor, S.; Tyagi, A.K. Genome-wide identification of $\mathrm{C} 2 \mathrm{H} 2$ zinc-finger gene family in rice and their phylogeny and expression analysis. Plant Mol. Biol. 2007, 65, 467-485. [CrossRef] [PubMed]

7. Sakamoto, H.; Maruyama, K.; Sakuma, Y.; Meshi, T.; Iwabuchi, M.; Shinozaki, K.; Yamaguchi-Shinozaki, K. Arabidopsis Cys2/His2type zinc-finger proteins function as transcription repressors under drought, cold, and high-salinity stress conditions. Plant. Physiol. 2004, 136, 2734-2746. [CrossRef]

8. Takatsuji, H.; Mori, M.; Benfey, P.N.; Ren, L.; Chua, N.H. Characterization of a zinc finger DNA-binding protein expressed specifically in Petunia petals and seedlings. Embo J. 1992, 11, 241-249. [CrossRef]

9. Cheuk, A.; Houde, M. Genome wide identification of C1-2i zinc finger proteins and their response to abiotic stress in hexaploid wheat. Mol. Genet. Genom. 2016, 291, 873-890. [CrossRef]

10. Liu, Z.; Coulter, J.A.; Li, Y.; Zhang, X.; Meng, J.; Zhang, J.; Liu, Y. Genome-wide identification and analysis of the Q-type C2H2 gene family in potato (Solanum tuberosum L.). Int. J. Biol. Macromol. 2020, 153, 327-340. [CrossRef]

11. Faraji, S.; Rasouli, S.H.; Kazemitabar, S.K. Genome-wide exploration of $\mathrm{C}_{2} \mathrm{H}_{2}$ zinc finger family in durum wheat (Triticum turgidum ssp. Durum): Insights into the roles in biological processes especially stress response. Biometals 2018, 31, 1019-1042. [CrossRef]

12. Zhang, H.; Liu, Y.; Wen, F.; Yao, D.; Wang, L.; Guo, J.; Ni, L.; Zhang, A.; Tan, M.; Jiang, M. A novel rice $\mathrm{C}_{2} \mathrm{H}_{2}$-type zinc finger protein, ZFP36, is a key player involved in abscisic acid-induced antioxidant defence and oxidative stress tolerance in rice. J. Exp. Bot. 2014, 65, 5795-5809. [CrossRef] [PubMed]

13. Yu, G.; Jiang, L.; Ma, X.; Xu, Z.; Liu, M.; Shan, S.; Cheng, X. A soybean C2H2-type zinc finger gene GmZF1 enhanced cold tolerance in transgenic Arabidopsis. PLoS ONE 2014, 9, e109399. [CrossRef]

14. Sun, B.; Zhao, Y.; Shi, S.; Yang, M.; Xiao, K. TaZFP1, a $\mathrm{C}_{2} \mathrm{H}_{2}$ type-ZFP gene of T. aestivum, mediates salt stress tolerance of plants by modulating diverse stress-defensive physiological processes. Plant Physiol. Biochem. 2019, 136, 127-142. [CrossRef] 
15. Zhang, H.; Ni, L.; Liu, Y.; Wang, Y.; Zhang, A.; Tan, M.; Jiang, M. The $\mathrm{C}_{2} \mathrm{H}_{2}$-type zinc finger protein ZFP182 is involved in abscisic acid-induced antioxidant defense in rice. J. Integr. Plant Biol. 2012, 54, 500-510. [CrossRef]

16. Liu, Z.; Chen, T.; Ma, L.; Zhao, Z.; Zhao, P.; Nan, Z.; Wang, Y. Global transcriptome sequencing using the Illumina platform and the development of EST-SSR markers in autotetraploid alfalfa. PLoS ONE 2013, 8, e83549. [CrossRef]

17. Jiao, Z.; Wang, L.; Du, H.; Wang, Y.; Wang, W.; Liu, J.; Huang, J.; Huang, W.; Ge, L. Genome-wide study of $\mathrm{C}_{2} \mathrm{H}_{2}$ zinc finger gene family in Medicago truncatula. BMC Plant Biol. 2020, 20, 401. [CrossRef]

18. Chen, H.; Zeng, Y.; Yang, Y.; Huang, L.; Tang, B.; Zhang, H.; Hao, F.; Liu, W.; Li, Y.; Liu, Y.; et al. Allele-aware chromosome-level genome assembly and efficient transgene-free genome editing for the autotetraploid cultivated alfalfa. Nat. Commun. 2020, 11, 2494. [CrossRef]

19. Li, W.; Godzik, A. Cd-hit: A fast program for clustering and comparing large sets of protein or nucleotide sequences. Bioinformatics 2006, 22, 1658-1659. [CrossRef] [PubMed]

20. El-Gebali, S.; Mistry, J.; Bateman, A.; Eddy, S.R.; Aurélien, L.; Potter, S.C.; Matloob, Q.; Richardson, L.J.; Salazar, G.A.; Alfredo, S. The Pfam protein families database in 2019. Nucleic Acids Res. 2019, 47, D427-D432. [CrossRef]

21. Schultz, J.; Copley, R.R.; Doerks, T.; Ponting, C.P.; Bork, P. SMART: A web-based tool for the study of genetically mobile domains. Nucleic Acids Res. 2000, 28, 231-234. [CrossRef]

22. Gasteiger, E.; Gattiker, A.; Hoogland, C.; Ivanyi, I.; Appel, R.D.; Bairoch, A. ExPASy: The proteomics server for in-depth protein knowledge and analysis. Nucleic Acids Res. 2003, 31, 3784-3788. [CrossRef]

23. Horton, P.; Obayashi, T.; Fujita, N.; Naoya, F.; Hajime, H.; Adams-Collier, C.J.; Kenta, N. WoLF PSORT: Protein localization predictor. Nucleic Acids Res. 2007, 35, W585-W587. [CrossRef]

24. Larkin, M.A.; Blackshields, G.; Brown, N.P.; Chenna, R.; McGettigan, P.A.; McWilliam, H.; Valentin, F.; Wallace, I.M.; Wilm, A.; Lopez, R.; et al. Clustal W and Clustal X version 2.0. Bioinformatics 2007, 23, 2947-2948. [CrossRef]

25. Guo, A.; Zhu, Q.; Gu, X.; Ge, S.; Yang, J.; Luo, J. Genome-wide identification and evolutionary analysis of the plant specific SBP-box transcription factor family. Gene 2008, 418, 1-8. [CrossRef]

26. Bailey, T.L.; Boden, M.; Buske, F.A.; Frith, M.; Grant, C.E.; Clementi, L.; Ren, J.; Li, W.W.; Noble, W.S. MEME SUITE: Tools for motif discovery and searching. Nucleic Acids Res. 2009, 37, W202-W208. [CrossRef]

27. Liu, Q.; Wang, Z.; Xu, X.; Zhang, H.; Li, C. Genome-wide analysis of $\mathrm{C}_{2} \mathrm{H}_{2}$ zinc-finger family transcription factors and their responses to abiotic stresses in poplar (Populus trichocarpa). PLoS ONE 2015, 10, e0134753. [CrossRef]

28. Chen, C.; Chen, H.; Zhang, Y.; Thomas, H.R.; Frank, M.H.; He, Y.; Xia, R. TBtools: An integrative toolkit developed for interactive analyses of big biological data. Mol. Plant 2020, 13, 1194-1202. [CrossRef]

29. Librado, P.; Rozas, J. DnaSP v5: A software for comprehensive analysis of DNA polymorphism data. Bioinformatics 2009, 25, 1451-1452. [CrossRef]

30. Camacho, C.; Coulouris, G.; Avagyan, V.; Ma, N.; Papadopoulos, J.; Bealer, K.; Madden, T.L. BLAST+: Architecture and applications. BMC Bioinform. 2009, 10, 421. [CrossRef] [PubMed]

31. Li, Z.; Chen, X. Research advances on plant inducible promoters and related cis-acting elements. Biotechnol. 2015, $31,8-15$.

32. Zhou, Q.; Luo, D.; Chai, X.; Wu, Y.; Wang, Y.; Nan, Z.; Yang, Q.; Liu, W.; Liu, Z. Multiple regulatory networks are activated during cold stress in Medicago sativa L. Int. J. Mol. Sci 2018, 19, 3169. [CrossRef]

33. Luo, D.; Wu, Y.; Liu, J.; Zhou, Q.; Liu, W.; Wang, Y.; Yang, Q.; Wang, Z.; Liu, Z. Comparative transcriptomic and physiological analyses of Medicago sativa L. indicates that multiple regulatory networks are activated during continuous ABA treatment. Int $J$. Mol. Sci 2018, 20, 47. [CrossRef]

34. Luo, D.; Zhou, Q.; Wu, Y.; Chai, X.; Liu, W.; Wang, Y.; Yang, Q.; Wang, Z.; Liu, Z. Full-length transcript sequencing and comparative transcriptomic analysis to evaluate the contribution of osmotic and ionic stress components towards salinity tolerance in the roots of cultivated alfalfa (Medicago sativa L.). BMC Plant Biol. 2019, 19, 32. [CrossRef]

35. Mao, P.; Jin, X.; Bao, Q.; Mei, C.; Zhou, Q.; Min, X.; Liu, Z. WRKY Transcription factors in Medicago sativa L.: Genome-wide identification and expression analysis under abiotic stress. DNA Cell Biol. 2020, 39, 2212-2225. [CrossRef]

36. Gourcilleau, D.; Lenne, C.; Armenise, C.; Moulia, B.; Julien, J.L.; Bronner, G.; Leblanc-Fournier, N. Phylogenetic study of plant Q-type $\mathrm{C}_{2} \mathrm{H}_{2}$ zinc finger proteins and expression analysis of poplar genes in response to osmotic, cold and mechanical stresses. DNA Res. 2011, 18, 77-92. [CrossRef]

37. Li, Y.; Sun, A.; Wu, Q.; Zou, X.; Chen, F.; Cai, R.; Xie, H.; Zhang, M.; Guo, X. Comprehensive genomic survey, structural classification and expression analysis of $\mathrm{C}_{2} \mathrm{H}_{2}$-type zinc finger factor in wheat (Triticum aestivum L.). Plant Mol. Biol. 2021, 21, 380. [CrossRef]

38. Sun, S.; Guo, S.; Yang, X.; Bao, Y.; Tang, H.; Sun, H.; Huang, J.; Zhang, H. Functional analysis of a novel Cys2/His2-type zinc finger protein involved in salt tolerance in rice. J. Exp. Bot. 2010, 61, 2807-2818. [CrossRef]

39. Kam, J.; Gresshoff, P.M.; Shorter, R.; Xue, G. The Q-type $\mathrm{C}_{2} \mathrm{H}_{2}$ zinc finger subfamily of transcription factors in Triticum aestivum is predominantly expressed in roots and enriched with members containing an EAR repressor motif and responsive to drought stress. Plant Mol. Biol. 2008, 67, 305-322. [CrossRef]

40. Dong, X.; Deng, H.; Ma, W.; Zhou, Q.; Liu, Z. Genome-wide identification of the MADS-box transcription factor family in autotetraploid cultivated alfalfa (Medicago sativa L.) and expression analysis under abiotic stress. BMC Genom. 2021, 22, 603. [CrossRef] [PubMed] 
41. Li, J.; Liu, X. Genome-wide identification and expression profile analysis of the Hsp20 gene family in Barley (Hordeum vulgare L.). Peer] 2019, 7, e6832. [CrossRef] [PubMed]

42. Uehara, Y.; Takahashi, Y.; Berberich, T.; Miyazaki, A.; Takahashi, H.; Matsui, K.; Ohme-Takagi, M.; Saitoh, H.; Terauchi, R.; Kusano, T. Tobacco ZFT1, a transcriptional repressor with a Cys2/His2 type zinc finger motif that functions in spermine-signaling pathway. Plant Mol. Biol. 2005, 59, 435-448. [CrossRef] [PubMed]

43. Weingartner, M.; Subert, C.; Sauer, N. LATE, a C (2) H (2) zinc-finger protein that acts as floral repressor. Plant J. 2011, 68, 681-692. [CrossRef]

44. Payne, T.; Johnson, S.D.; Koltunow, A.M. KNUCKLES (KNU) encodes a $\mathrm{C}_{2} \mathrm{H}_{2}$ zinc-finger protein that regulates development of basal pattern elements of the Arabidopsis gynoecium. Development 2004, 131, 3737-3749. [CrossRef]

45. Cannon, S.B.; Mitra, A.; Baumgarten, A.; Young, N.D.; May, G. The roles of segmental and tandem gene duplication in the evolution of large gene families in Arabidopsis thaliana. BMC Plant Biol. 2004, 4, 10. [CrossRef] [PubMed]

46. Zhou, Q.; Jia, C.; Ma, W.; Cui, Y.; Jin, X.; Luo, D.; Min, X.; Liu, Z. MYB transcription factors in alfalfa (Medicago sativa): Genome-wide identification and expression analysis under abiotic stresses. PeerJ 2019, 7, e7714. [CrossRef]

47. Yamaguchi-Shinozaki, K.; Shinozaki, K. Transcriptional regulatory networks in cellular responses and tolerance to dehydration and cold stresses. Annu. Rev. Plant Biol. 2006, 57, 781-803. [CrossRef]

48. Yamaguchi-Shinozaki, K.; Shinozaki, K. A novel cis-acting element in an Arabidopsis gene is involved in responsiveness to drought, low-temperature, or high-salt stress. Plant Cell 1994, 6, 251-264. [PubMed]

49. Wang, L.Y.; Zhang, Y.; Fu, X.; Zhang, T.; Ma, J.; Zhang, L.; Qian, H.; Tang, K.; Li, S.; Zhao, J. Molecular cloning, characterization, and promoter analysis of the isochorismate synthase (AaICS1) gene from Artemisia annua. J. Zhejiang Univ. Sci. B 2017, 18, 662-673. [CrossRef]

50. Ahuja, I.; Vos, R.C.H.; Bones, A.M.; Hall, R.D. Plant molecular stress responses face climate change. Trends. Plant Sci. 2010, 15, 664-674. [CrossRef] [PubMed]

51. Vogel, J.T.; Zarka, D.G.; Buskirk, H.A.V.; Fowler, S.G.; Thomashow, M.F. Roles of the CBF2 and ZAT12 transcription factors in configuring the low temperature transcriptome of Arabidopsis. Plant J. 2005, 41, 195-211. [CrossRef] [PubMed]

52. Sugano, S.; Kaminaka, H.; Rybka, Z.; Catala, R.; Salinas, J.; Matsui, K.; Ohme-Takagi, M.; Takatsuji, H. Stress-responsive zinc finger gene ZPT2-3 plays a role in drought tolerance in petunia. Plant J. 2003, 36, 830-841. [CrossRef] [PubMed]

53. Tian, Z.; Zhang, Y.; Liu, J. Novel potato $\mathrm{C}_{2} \mathrm{H}_{2}$-type zinc finger protein gene, StZFP1, which responds to biotic and abiotic stress, plays a role in salt tolerance. Plant Biol. 2010, 12, 689-697. [CrossRef] [PubMed]

54. Mittler, R.; Kim, Y.; Song, L.; Coutu, J.; Coutu, A.; Ciftci-Yilmaz, S.; Lee, H.; Stevenson, B.; Zhu, J. Gain-and loss-of-function mutations in Zat10 enhance the tolerance of plants to abiotic stress. FEBS Lett. 2006, 580, 6537-6542. [CrossRef] [PubMed]

55. Cao, J.; Sun, L.; Li, J.; Zhou, C.; Cheng, L.; Chen, K.; Yan, B.; Qian, W.; Ma, Q.; Duan, W. A novel three miRNA signature predicts survival in cholangiocarcinoma based on RNASeq data. Oncol. Rep. 2018, 40, 1422-1434.

56. Zhang, T.; Chen, H.; Qi, L.; Zhang, J.; Wu, R.; Zhang, Y.; Sun, Y. Transcript profiling identifies early response genes against FMDV Infection in PK-15 cells. Viruses 2018, 10, 364. [CrossRef] [PubMed]

57. Zhou, Q.; Chen, T.; Wang, Y.; Liu, Z. The development of 204 novel EST-SSRs and their use for genetic diversity analyses in cultivated alfalfa. Biochem. Syst. Ecol. 2014, 57, 227-230. [CrossRef] 